\title{
The feasibility of implementing food-based dietary guidelines in the South African primary-school curriculum
}

\author{
Kim A Nguyen ${ }^{1,2}$, Anniza de Villiers ${ }^{2}$, Jean M Fourie ${ }^{2, *}$, Lesley T Bourne ${ }^{1,3}$ and \\ Michael K Hendricks ${ }^{1}$ \\ 'School of Child and Adolescent Health, University of Cape Town, Rondebosch, Cape Town, South Africa: \\ ${ }^{2}$ Chronic Diseases of Lifestyle Unit, Medical Research Council, PO Box 19070, Tygerberg 7505, South Africa: \\ ${ }^{3}$ Environment \& Health Research Unit, Medical Research Council, Parow, Cape Town, South Africa
}

Submitted 6 March 2013: Final revision received 25 July 2013: Accepted 15 October 2013: First published online 27 November 2013

\begin{abstract}
Objective: To explore the perceptions of educators from the Western Cape Province about the feasibility of implementing South African food-based dietary guidelines (FBDG) in the national curriculum of primary schools.

Design: Combined quantitative and qualitative methods. We report on the quantitative component.

Setting: Twelve public primary schools of different socio-economic status in three education districts of the Western Cape: Metro Central, Metro East and Cape Winelands.

Subjects: Educators ( $n$ 256) participated in the self-completed questionnaire survey.

Results: Educators assessed that FBDG were appropriate to South African schoolchildren (94\%), could be used as an education tool (97\%) and fill gaps in the current curriculum about healthy dietary habits (91\%). Besides Life Orientation, FBDG could be taught in other learning areas from grades 3 to 7 (9-13 years old). Important barriers to implementing FBDG in the curriculum were educators' workload (61\%), insufficient time (46\%), learners' disadvantaged background (43\%) and educators' lack of knowledge (33\%). Other approaches to teach children about FBDG included linking these to the National School Nutrition Programme (82\%), school tuck shops (79\%), parent meetings (75\%), school nutrition policy (73\%) and school assembly (57\%). Educators in high-income schools perceived that learners' lifestyle was significantly worse $(P<0 \cdot 001)$ and that tuck shops and the school assembly were the best means to teach pupils about FBDG $(P<0 \cdot 001$ and $P<0 \cdot 05)$.

Conclusions: Implementing FBDG in the national school curriculum is seen as important together with optimizing the school physical environment. Key factors required for successful implementation in the curriculum are sufficient educational materials, adequate time allocation and appropriate educator training.
\end{abstract}

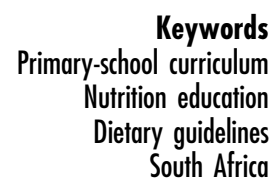

Implementing food-based dietary guidelines (FBDG) in the school curriculum is recommended worldwide as a cost-effective intervention in preventing the development of non-communicable diseases and the consequences of malnutrition $^{(1-3)}$. Non-communicable diseases such as heart disease, stroke, cancer, chronic respiratory disease and diabetes were high on the agenda at the WHO Global Forum and the UN meeting in 2011. These diseases caused 36 million deaths in 2008 and were the leading causes of mortality globally. A third of these deaths occurred before age 60 years, mainly in developing countries $^{(4)}$. The WHO projects that by 2030, noncommunicable diseases will account for $77 \%$ of deaths worldwide ${ }^{(5)}$.
A major factor contributing to non-communicable diseases is the increasing rate of overweight and obesity. In the South African Demographic and Health Survey, the Department of Health found that nearly two-thirds of women and half of men older than 35 years were overweight or obese in $2003^{(6)}$. Rising overweight and obesity rates among schoolchildren are of concern according to a number of studies which show the coexistence of underand overnutrition ${ }^{(7-9)}$. According to these studies, $22 \%$ of girls and $17 \%$ of boys aged $6-13$ years were overweight or obese, $18 \%$ of children aged 1-9 years were stunted and $10 \%$ were underweight ${ }^{(7-9)}$. In a systematic review, data from the Western Cape Province showed a prevalence of overweight and obesity among teenagers of $19 \cdot 9 \%$ 
and $7 \cdot 1 \%$, respectively, whereas stunting and underweight rates in children aged $1-9$ years were $12 \cdot 0 \%$ and $8 \cdot 2 \%$, respectively ${ }^{(10)}$. Contributing to this burden is a lack of physical activity among children and adults, especially in urban and peri-urban areas ${ }^{(6,9)}$. There is a need to address unhealthy lifestyles through health promotion, education and advocacy regarding healthy dietary practices and physical activity among all sectors of the public.

The South African Government endorsed the global strategy on diet and physical activity by developing and implementing the FBDG for South African adults and schoolchildren aged 7 years and older ${ }^{(11)}$. According to Vorster et al., these guidelines were developed by a multidisciplinary working group comprising scientists from the Nutrition Society of South Africa, the Association for Dietetics in South Africa, the Medical Research Council, the national Department of Health, UNICEF, the agriculture sector, the food industry and the $\mathrm{FAO}^{(12)}$. The guidelines were based on the best currently available scientific evidence on the relationship between nutrition and disease, and were envisaged for use as an educational tool to improve public awareness and the practice of healthy food consumption. They aim at reducing the growing burden of chronic diseases associated with obesity and overnutrition, as well as nutritional disorders associated with poverty and undernutrition.

Because of unhealthy diets and the rise of chronic diseases coupled with undernutrition and micronutrient deficiency among the South African population, strengthening the school curriculum in terms of nutrition and healthy lifestyles is essential. At an international level, most countries that have implemented FBDG recommend educators as effective channels of communication ${ }^{(13)}$. Since children spend most of their time at school and dietary habits are acquired in childhood, educators could promote healthy dietary habits and physical activity ${ }^{(14)}$. However, the feasibility and impact of implementing FBDG in school curricula have not yet been evaluated ${ }^{(15,16)}$.

At the time of the present study, the national school curriculum in South Africa included nutrition and healthy lifestyles in the learning area of Life Orientation (LO). The Outcomes-Based Education curriculum allowed educators to select their own teaching materials to reach the outcome assessment standards ${ }^{(17,18)}$. This learning area has subsequently been changed to the subject Life Skills and the aim of the new curriculum is 'to be more specific on what is to be taught and learnt, ${ }^{\text {(19) }}$.

Recommendations by the Department of Health and academic institutions to implement FBDG in the school curriculum have been made and the new curriculum includes them in grade 5 as part of a $3 \mathrm{~h}$ /year allocation to 'health and environmental responsibility'(12,20). Furthermore, the newly launched Integrated School Health Policy includes the FBDG as basic content for the nutrition education component of a school health programme ${ }^{(21)}$.
The revised Integrated School Health Policy explicitly indicates that health education and nutrition in particular should be provided to learners at schools through the national curriculum of the Life Skills subject. This should also be supplemented with additional co-curricular/ school-based activities or programmes, as the timetabling may not be adequate to fully address the issues.

However, no research to assess the feasibility of implementing the South African FBDG has been done within school settings. Therefore, the present study aimed to assess educators' perceptions of learners' dietary habits and physical activity, and to explore the feasibility of and possible barriers to implementing these guidelines within the school curriculum. The findings could possibly contribute towards optimizing nutrition education within schools and ultimately the adoption of healthy lifestyles within a future adult population. Notably, the South African FBDG are currently under revision and should be available in the near future.

\section{Methods}

\section{Study design}

The present cross-sectional and descriptive study made use of quantitative and qualitative methodologies. We report on the quantitative component of the study.

\section{Population and sampling}

The study population comprised all educators and principals at public primary schools in three educational districts in the Western Cape Province of South Africa (Fig. 1). Schools were stratified according to the languages registered and socio-economic status (SES) of the schools based on school quintiles. The school quintile is a mechanism that aims at improving equity in financing education. Each school is ranked into one of five quintiles, with quintile 1 (Q1) being the poorest and quintile 5 (Q5) being the least poor, based on rates of income, unemployment and illiteracy within the school catchment area. Schools in Q1 and Q2 are no-fee schools and considered as low-income schools, while Q3 schools are middle-income ones. Schools in Q4 and Q5 are fee-paying and regarded as high-income schools. The low-income schools receive up to six times more funding from the government than the higher-income schools ${ }^{(22,23)}$.

The education districts of Metro Central, Metro East and Cape Winelands, which represent urban, peri-urban and rural areas of the Western Cape, were purposively chosen. The school sampling aimed at achieving a balanced sample regarding the proportions of schools located in each educational district according to language and quintiles to represent the range of schools in the three educational districts. Twelve schools among the 418 schools in these educational districts were randomly selected for the present study and included four schools 


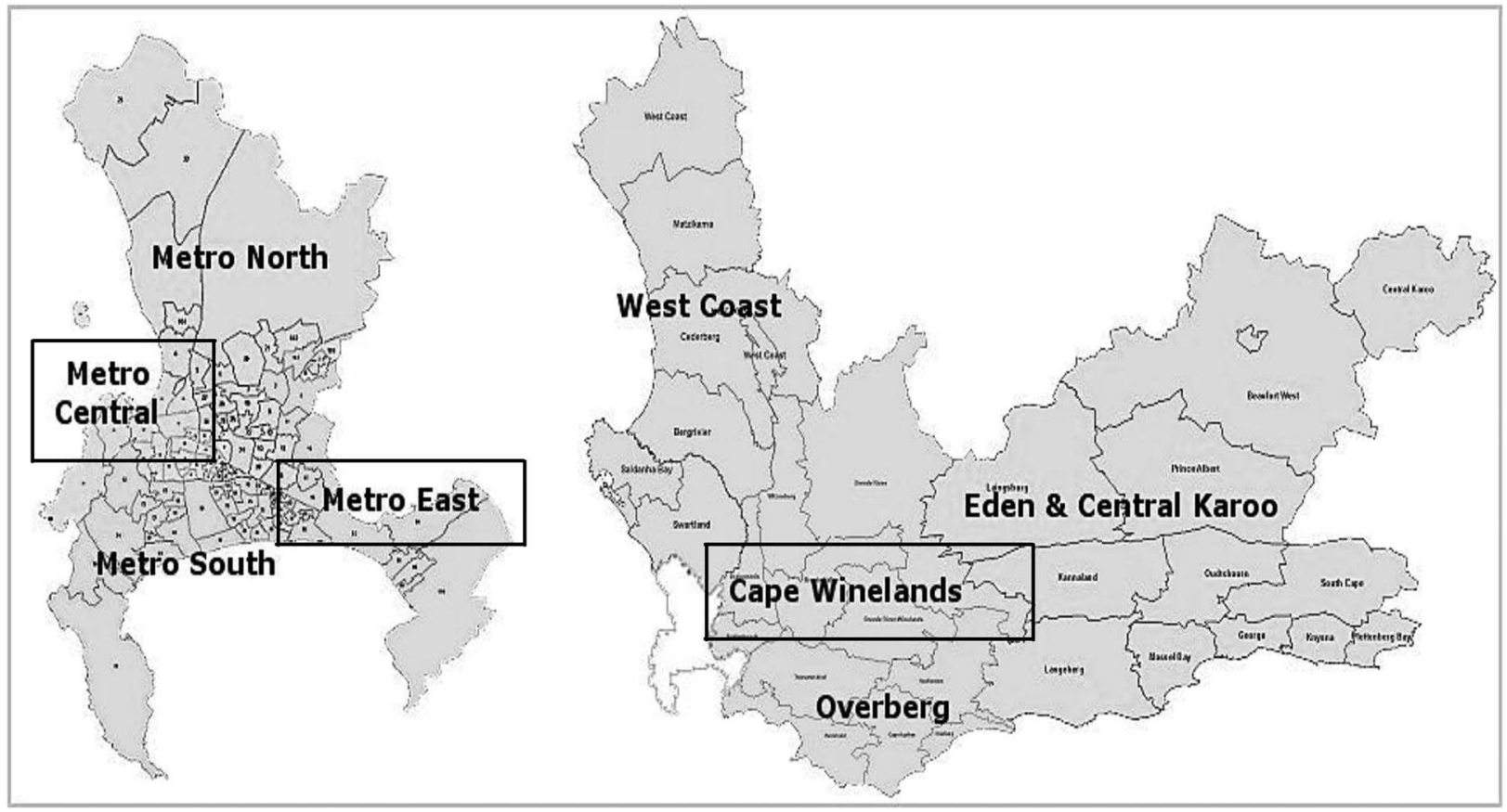

Fig. 1 Education districts in the Western Cape, South Africa

from Metro Central, two from Metro East and six from the Cape Winelands. In terms of language, the sample comprised four English, five Afrikaans and three bilingual Xhosa/English schools, as these are the major official languages at schools in these educational districts. These also represented five schools in the low-income group, two in the middle-income group and five from the highincome group relating to the quintile system. All twelve selected schools agreed to participate in the study.

The study was approved by the Research Ethics Committee of the University of Cape Town (HREC.REF: 498/2010) and permission for conducting research at schools was given by the Department of Education of the Western Cape. All participants were fully informed about the objectives, procedures and confidentiality aspects of the study and provided written consent for participating.

\section{Data collection}

To gather information on perceptions about the feasibility of implementing FBDG in the curriculum, educators who were employed at the twelve schools completed a self-administered structured questionnaire. Experts in the development of FBDG and primary-school-based interventions were involved in the development process of the questionnaire. The questionnaire was piloted at two schools and modified to enhance its validity before being used for the main study.

The educators met in the school staff room and after a brief presentation and provision of informed consent, the questionnaire was completed. Although 256 (77\%) out of 332 educators who were employed at the twelve schools at the time of the study participated in the survey, some of them omitted answering some of the questions. During the sessions, FBDG fact sheets of the Department of Health were disseminated to the educators as a resource supplement for the purpose of the study.

\section{Data analysis}

Data obtained from the self-administered questionnaire were analysed using the statistical software package STATA version 11. Descriptive statistical analyses and frequency tables of variables were performed. Associations between categorical variables were assessed by the $\chi^{2}$ test or if expected frequencies were $<5$, by Fisher's exact test. A $P$ value $<0.05$ was indicative of statistical significance. The $95 \%$ confidence interval for population proportion was calculated. Results are reported by SES groups, where low SES includes Q1 and Q2 schools, middle SES comprises Q3 schools and high SES Q4 and Q5 schools.

\section{Results}

Two hundred and fifty-six educators participated in the study, of whom sixty-four (25\%) were male and 192 (75\%) were female. Schools at which the educators taught were classified as low (36\%, $n$ 91), middle (27\%, $n 68)$ and high $(38 \%, n$ 97) SES. The median number of learners per educator was significantly higher for lowand middle-income compared with high-income schools (39) and 38.5 v. 36, $P<0 \cdot 001$ ). 
Table 1 Educators' perceptions* of learners' dietary habits and physical activity according to school socio-economic status (SES); educators $(n 256)$ from twelve public primary schools of different socio-economic status in three education districts of the Western Cape Province, South Africa

\begin{tabular}{|c|c|c|c|c|c|c|c|c|c|}
\hline \multirow[b]{3}{*}{ Behaviour outcomes } & \multicolumn{6}{|c|}{ SES } & & & \multirow[b]{3}{*}{$P$ value } \\
\hline & \multicolumn{2}{|c|}{ Low $(n 91)$} & \multicolumn{2}{|c|}{ Middle ( $n$ 68) } & \multicolumn{2}{|c|}{ High ( $n$ 97) } & \multicolumn{2}{|c|}{ Total (n 256) } & \\
\hline & $\%$ & $95 \% \mathrm{Cl}$ & $\%$ & $95 \% \mathrm{Cl}$ & $\%$ & $95 \% \mathrm{Cl}$ & $\%$ & $95 \% \mathrm{Cl}$ & \\
\hline Have a healthy breakfast at home & 11 & 5,19 & 10 & 4,20 & 11 & 5,19 & 11 & 7,15 & 0.873 \\
\hline Bring a healthy lunch box to school & 19 & 11,28 & 20 & 12,32 & 21 & 13,30 & 20 & 15,25 & 0.054 \\
\hline Eat a variety of foods every day & 30 & 21,40 & 21 & 12,32 & 13 & 7,22 & 21 & 16,27 & 0.001 \\
\hline Drink enough safe and clean water & 54 & 43,64 & 46 & 33,58 & 28 & 19,38 & 42 & 36,48 & $<0.001$ \\
\hline Eat too much fatty foods every day & 61 & 50,71 & 59 & 46,71 & 77 & 68,85 & 66 & 60,72 & 0.026 \\
\hline Eat too much sugary foods and drinks & 86 & 77,92 & 82 & 71,91 & 95 & 88,98 & 88 & 84,92 & 0.021 \\
\hline Engage in sport activity & 60 & 49,70 & 42 & 30,54 & 24 & 16,34 & 42 & 36,48 & $<0.001$ \\
\hline
\end{tabular}

*Percentage of educators answering 'yes' to the behaviour.

No statistically significant differences were noted for age or years of overall and LO teaching experience of educators based on the SES of schools. The median age of educators was 45 years with 20 years of teaching experience. Experience of the educators varied from grades $\mathrm{R}$ to 7 (6-13 years old) and the proportion was distributed almost equally across the grades $(\sim 20 \%)$ except for grade $\mathrm{R}(8 \%)$. In terms of subjects, LO, Mathematics and Literacy were the three main subjects in which educators in the present study had the most experience.

Overall, $178(70 \%)$ of the educators who answered questions about learners' dietary habits and physical activity perceived that the learners had unhealthy dietary habits $(87 \%, n 155)$ and were inactive $(52 \%, n$ 93). Educators' perceptions about learners' dietary habits and physical activity were further assessed in terms of the FBDG recommendations as outlined in Table 1. Eleven per cent $(n 28)$ perceived that very few learners had a healthy breakfast before school, $20 \%(n 51)$ that learners brought a healthy lunch box to school and $21 \%$ ( $n$ 54) thought learners ate a variety of foods every day. On the other hand, $42 \%$ ( $n$ 107) thought that learners drank enough safe, clean water. A high proportion of learners were perceived to regularly consume fatty foods $(66 \%$, $n$ 170) and excessive sugary/sweet foods and drinks ( $88 \%, n$ 226). A significantly higher proportion of educators from the high-income schools reported that their learners consumed excessive fatty foods $(77 \%, n 75)$ and sugary foods and drinks $(95 \%, n 92)$ compared with educators in the low-income schools $(61 \%$ and $86 \%$, respectively; $P<0 \cdot 05$ ). About $26 \%$ ( $n$ 67) of educators did not know whether learners had a healthy breakfast before school, or ate a variety of foods daily, or ate too much fatty foods. No significant differences were noted regarding educators' perceptions about other eating habits of learners, with about a third not knowing the learners' habits.

Significantly fewer educators at high-income schools $(24 \%, n 23)$ compared with those at middle-income $(42 \%, n$ 28) and low-income $(60 \%, n$ 54) schools indicated that learners participated in physical activity $(P<0 \cdot 001)$.

When asked to what extent educators thought learners understood specific topics on nutrition and healthy lifestyles, more than half answered 'poor' and 'very poor'. Topics rated as poor included the importance of a balanced diet $(66 \%, n 168)$ and of physical activity $(58 \%$, $n$ 148). Learners' knowledge of nutrients in food ( $76 \%$, $n 195)$, food safety, labelling and packaging $(81 \%, n 207)$, and planning a good and healthy meal $(80 \%, n 204)$ was also rated poor by the educators.

Regarding their perceptions of learners' weight status, more than half of the educators $(56 \%, n 140)$ expressed concern about learners being overweight or obese, while less than half ( $46 \%, n$ 116) indicated that learners' underweight was of concern. Being overweight or obese seemed to be more of a concern than underweight, and more of a problem in the high-income schools $(70 \% v$. $50 \%$ and $45 \%$ in middle- and low-income schools, respectively; $P<0.05)$. In contrast, perceptions about underweight among learners were still higher in the lower-income schools, but this was not statistically significant $(55 \%$ in low-, $49 \%$ in middle- and $37 \%$ in high-income schools).

No statistically significant differences were found in the main topics taught on nutrition, healthy dietary habits and physical activity which were covered in the curriculum as listed by the educators. The importance of drinking lots of safe, clean water and the benefits of physical activity were taught by $95 \%$ of educators ( $n$ 243). Other topics that were listed included: the importance of a balanced diet (93\%, $n$ 238); food groups (89\%, $n$ 227); healthy eating patterns ( $89 \%, n 227)$; nutrients in foods $(84 \%, n 215)$; planning healthy meals $(84 \%, n 215)$; and food safety/ labelling/packaging ( $77 \%, n$ 197). Most of the educators $(77 \%, n$ 197) reported being satisfied with what they taught learners about nutrition and healthy lifestyles; however, almost all $(99 \%, n 253)$ mentioned that education in these areas could be improved in schools.

To improve nutrition education in schools, educators selected teaching through the curriculum $(95 \%, n$ 238), 
optimizing the school environment ( $92 \%, n$ 232), implementing a school nutrition policy ( $92 \%, n$ 230) and obtaining support from the Department of Education (91\%, $n$ 227) as possible approaches. There were no significant differences according to SES. Other approaches included enlisting the involvement of parents, employing physical educators and inviting a dietitian to teach nutrition and dietary habits in schools.

In terms of resources used for teaching nutrition and dietary habits, educators indicated using prescribed textbooks (99\%, $n$ 247), magazines and newspapers (96\%, $n$ 240) irrespective of the schools' SES. Very few educators mentioned using nutritional materials developed by South African initiatives for schools such as the Pick 'n' Pay School Club (21\%, $n$ 52), the Hearty School programme manual $(16 \%, n 40)$, the Woolworths Making the Difference programme (13\%, $n$ 33), the

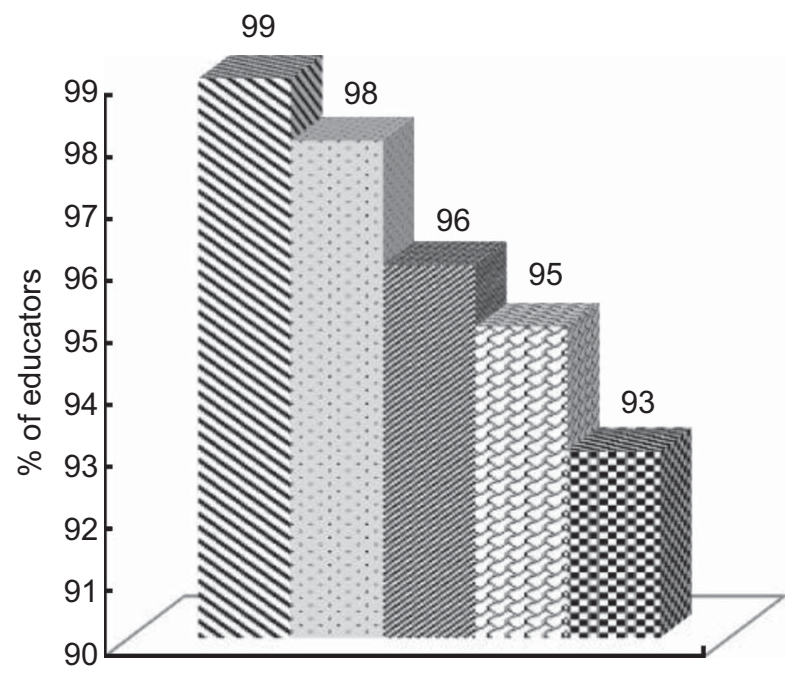

Fig. 2 Subjects $(\%$, Languages; $\because$, Natural Science; $*$, Economic \& Management Science; $\longleftrightarrow$, Mathematics; : Human \& Social Science) in which educators thought food-based dietary guidelines could be taught; educators ( $n$ 256) from twelve public primary schools of different socio-economic status in three education districts of the Western Cape Province, South Africa
Discovery Vitality schools programme $(6 \%, n 15)$ and the HealthKick manual $(5 \%, n 13)$. Internet use was reported by less than half of the educators (49\%, $n$ 122).

Regarding educators' perceptions of the FBDG, only $26 \%$ of them ( $n$ 67) had heard about these at the time of the study. After reading the FBDG, almost all of them thought the guidelines were interesting (96\%, $n$ 244), easy to interpret $(94 \%, n 238)$, appropriate for South Africans (94\%, $n$ 238), practical (92\%, $n$ 233), suitable to teach at primary schools $(97 \%, n 246)$ and able to address the gaps in the current curriculum (91\%,n 231).

In terms of subjects, educators indicated that besides implementing the FBDG in the LO curriculum, they could also be taught in subjects such as Languages (99\%, $n$ 204), Natural Science (98\%, $n$ 209), Economic \& Management Studies (96\%, $n$ 188), Mathematics (95\%, $n$ 180) and Human \& Social Science (93\%, $n$ 167; Fig. 2). Most educators thought the FBDG could be taught to learners from grade 3 (age 9 years) onwards. However, more than 90\% ( $n$ 227) considered grades 6 and 7 (ages 12 and 13 years) as being best suited to teach these guidelines.

Most educators $(96 \%, n$ 242) recommended various other ways of implementing the FBDG in the school environment. These were the National School Nutrition Programme $(82 \%, n$ 198) and school tuck shops (79\%, $n$ 191). Other recommendations included using school parent meetings to educate parents about the FBDG (75\%, $n$ 182), a school nutrition policy ( $73 \%, n 177)$, the school newsletter (69\%, $n$ 167) and the school assembly (57\%, $n$ 138). Library time and physical education were also seen as good opportunities to teach the FBDG (Table 2). School tuck shops and the school assembly were significantly favoured by the educators from the high-income schools in comparison to the lower-income schools $(P<0 \cdot 05)$.

Figure 3 highlights important barriers to implementing the FBDG in the curriculum. Despite positive perceptions about the implementation, most educators ( $85 \%, n$ 208) said that various challenges needed to be overcome. Important barriers identified were a high administrative

Table 2 Educators' perceptions* of other avenues for implementing the food-based dietary guidelines according to school socio-economic status (SES); educators $(n$ 256) from twelve public primary schools of different socio-economic status in three education districts of the Western Cape Province, South Africa

\begin{tabular}{|c|c|c|c|c|c|c|c|c|c|}
\hline \multirow[b]{3}{*}{ Possible avenues } & \multicolumn{6}{|c|}{ SES } & & & \multirow[b]{3}{*}{$P$ value } \\
\hline & \multicolumn{2}{|c|}{ Low $(n 87)$} & \multicolumn{2}{|c|}{ Middle $(n 62)$} & \multicolumn{2}{|c|}{ High ( $n$ 93) } & \multicolumn{2}{|c|}{ Total (n 242) } & \\
\hline & $\%$ & $95 \% \mathrm{Cl}$ & $\%$ & $95 \% \mathrm{Cl}$ & $\%$ & $95 \% \mathrm{Cl}$ & $\%$ & $95 \% \mathrm{Cl}$ & \\
\hline National School Nutrition Programme & 82 & 72,89 & 84 & 72,92 & 81 & 71,88 & 82 & 76,86 & $0 \cdot 876$ \\
\hline School tuck shop & 69 & 58,78 & 73 & 60,83 & 92 & 85,97 & 79 & 73,84 & $<0.001$ \\
\hline Parent meetings & 70 & 59,79 & 79 & 67,88 & 76 & 66,85 & 75 & 69,80 & $0 \cdot 711$ \\
\hline School policy & 70 & 59,79 & 76 & 63,86 & 74 & 64,83 & 73 & 67,79 & 0.423 \\
\hline School newsletters & 66 & 55,75 & 73 & 60,83 & 70 & 60,79 & 69 & 63,75 & 0.638 \\
\hline School assembly & 44 & 33,55 & 55 & 42,68 & 70 & 60,79 & 57 & 50,63 & 0.002 \\
\hline
\end{tabular}

*Percentage of educators suggesting to use the avenue. 


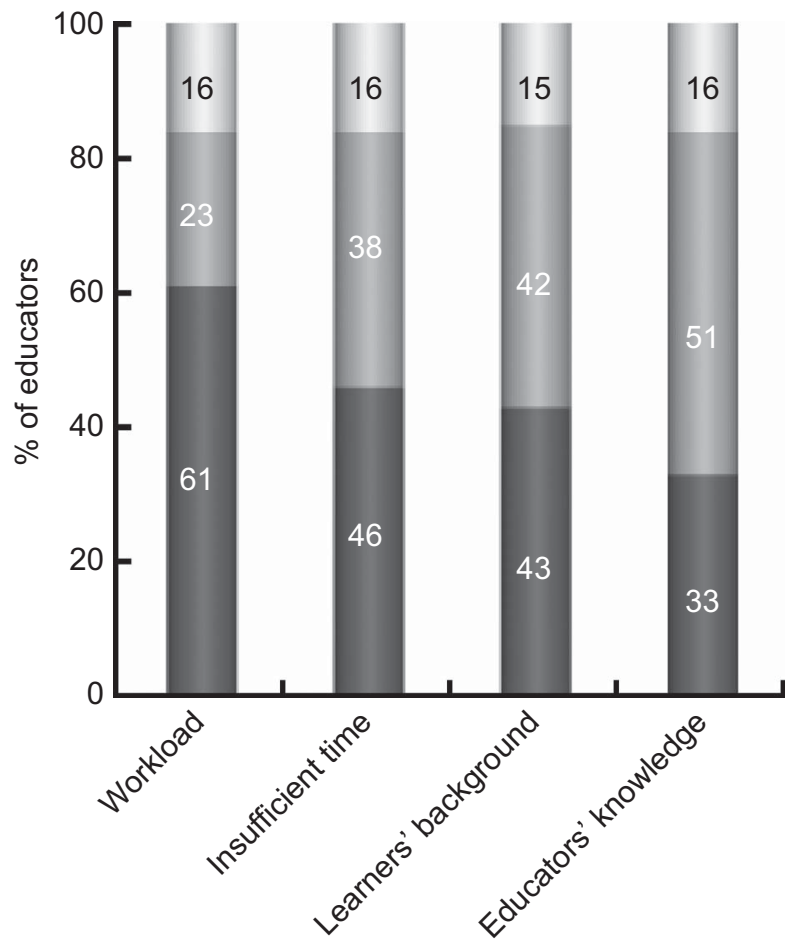

Fig. 3 Barriers ( , not rated; $\square$, less important; $\square$, important) identified by educators to implement the food-based dietary guidelines; educators ( $n$ 256) from twelve public primary schools of different socio-economic status in three education districts of the Western Cape Province, South Africa

workload (61\%, $n$ 113), insufficient time (46\%, $n$ 87), learners' disadvantaged background ( $43 \%, n$ 78) and educators' lack of knowledge about nutrition (33\%, $n$ 61). Of the $42 \%$ ( $n$ 75) who thought learners' disadvantaged background was a less important barrier, significantly more educators from high-income schools indicated this $(P<0 \cdot 001$; data not shown). Other barriers emerging from the data included the school's lack of finance and resources, lack of support from the school principals and educators as role models.

Educators admitted having limited knowledge of the FBDG that would constrain successful implementation. Most of them $(75 \%, n$ 192) indicated that training was necessary to provide them with essential knowledge to facilitate teaching FBDG more effectively. Improving educators' knowledge about the FBDG and skills on integrating the messages into their learning areas were cited as the main reasons why training was needed.

\section{Discussion}

Findings from the present study affirm the necessity of implementing the FBDG within school settings. However, until now, aspects which the study addressed have been neglected regarding the implementation process.
Data revealed that the educators did not have many years of experience in teaching LO $(7 \cdot 5$ years $)$ although they generally had taught for as many as 20 years, irrespective of the SES of the schools. The few years of teaching LO could be related to the fact that this is a new learning area, which was introduced into the curriculum in $1997^{(18,24)}$.

Based on the perceptions of the educators, the learners' dietary practices and physical activity were not consistent with the FBDG recommendations. These findings support those of the National Food Consumption Survey and other studies which indicated that the dietary intake among South African children is inadequate in energy, micronutrients and fibre ${ }^{(25-28)}$. This may result from a lack of consumption of a variety foods as well as fruit and vegetables and excessive consumption of snack foods, frequently high in sugar. Furthermore, the educators in the present study indicated that learners were physically inactive. These perceptions about dietary practices and physical inactivity were more common in high-income schools than in the lower-income ones. This could be an indication that educators in high-income schools were better informed of learners' eating behaviour while at school, which could also explain why more educators in this setting favoured changes within the school environment, especially within the tuck shops. A survey undertaken by Reddy et al. in 2008, in a slightly older population, confirmed the perceptions of the educators regarding physical inactivity, with $42 \%$ of a sample of grade 8-10 (age 14-16 years) learners being found to be physically inactive ${ }^{(9)}$.

Along with this, poor knowledge of nutrition and healthy eating habits and lifestyle among learners and their parents emerged as an important factor contributing to learners' unhealthy food choices. Wardle et al. agreed that knowledge is of significance to one's food choices and that the promotion of healthy eating should include nutrition knowledge ${ }^{(29)}$. Furthermore, similar conclusions were made in a local study by Oldewage-Theron and Egal among primary-school learners in QwaQwa in the Free State Province ${ }^{(30)}$. These learners had many gaps in their nutrition knowledge as defined by FBDG. Developing and implementing school-based nutrition and physical education programmes for this age group to reinforce healthy eating in accordance with FBDG were recommended.

Most of the educators in our study indicated they covered several of the important topics on nutrition, healthy dietary habits and lifestyle in the LO curriculum. Although almost $80 \%$ of the educators indicated they were satisfied with what learners were being taught, there appeared to be a mismatch with what learners were taught and their actual knowledge about healthy dietary practices. According to Outcomes-Based Education methodology, currently implemented at schools, educators have to find their own teaching content to meet the 
assessment standards ${ }^{(17)}$. Therefore, it is not surprising that educators had difficulty in acknowledging that their selection of teaching materials was not optimal considering that this would reflect their professional competence.

Although the FBDG were published in 2004, only $26 \%$ of educators confirmed that they had heard of these guidelines at the time of the study. While a few private organizations used the guidelines for their nutrition education materials, much of this was experimental and few educators reported having access to these materials. These results indicate the lack of promotion of FBDG as an education tool by the Departments of Health and Education. This lack of promotion and advocacy has also been highlighted in a study by Keller and Lang on the implementation of FBDG in four countries (Chile, Germany, New Zealand and South Africa) ${ }^{(15)}$.

After having read the FBDG document, almost all educators considered this as a useful resource to be implemented in the curriculum of various subjects and grades at primary-school level. LO was assumed to be the best option, since this subject already focused on good nutrition and a healthy lifestyle in the curriculum. However, Rooth in her study expressed concerns that if all educators were to teach LO, this could result in the subject not being taught properly; or if integrated into other learning areas, LO could become invisible ${ }^{(24)}$. This argument appears to be in opposition to recommendations by Glasauer et al., who perceived nutrition as an entry point in establishing healthpromoting schools and that nutrition should be taught in various subjects at schools ${ }^{(31)}$. Furthermore, the results showed the educators relied mostly on prescribed textbooks (99\%) and nutrition articles in magazines and newspapers (96\%) in preparing their nutrition lessons. For this reason, it would be essential for the FBDG document to be included in the relevant textbooks if these guidelines are meant to be implemented in the national curriculum. An alternative option would be to make the FBDG available through media channels such as magazines and newspapers where educators are likely to access them.

Besides teaching the FBDG in the curriculum, most educators thought that optimizing the physical environment at schools was another important approach in implementing the guidelines and supporting informed decision making. The National School Nutrition Programme was mostly recommended as an avenue where the FBDG could be applied. This programme provides needy learners with a daily balanced meal at low-income schools. Therefore, this recommendation is especially relevant in the context that many learners do not have a healthy breakfast before school.

Another important target for implementing FBDG is school tuck shops. These and the food vendors nearby schools play a crucial role in influencing learners' food choices. The availability of unhealthy foods at low cost from these entities is seen as a key barrier to the promotion of healthy eating and nutrition at schools.
Various local studies show that most foods purchased at schools came from the tuck shop and were classified as unhealthy items ${ }^{(32-34)}$. Changing school tuck shops to healthier ones would provide learners with the opportunity to make healthier food choices. However, findings from studies revealed that the provision of only a healthy tuck shop did not effectively influence learners' attitudes and behaviours towards healthy eating. There is also a need for a multi-pronged approach that creates the best possible healthy environment at schools ${ }^{(34,35)}$.

Barriers to implementing FBDG in the primary-school curriculum, which our educators identified, have also been recognized in other studies. Limited time allocated for nutrition topics could possibly restrict educators from in-depth teaching about the FBDG although many were not aware of these guidelines before the present study. These time constraints were worsened by the educators' administrative workload and the high density of classes. While Rooth and Linda reported educators' overload hindering the preparation and planning of lessons against the Outcomes-Based Education assessments, and the study by Draper et al. cited that educators' workload and insufficient time allocation were major barriers to implementing school-based nutrition and physical programmes in South Africa ${ }^{(24,36,37)}$, the other important constraints educators highlighted were a lack of knowledge, especially about nutrition and healthy dietary habits, attributed to not being specialized in the subject (e.g. LO), lack of resources and a lack of training.

\section{Limitations of the study}

Although the present study is small, the data gathered may provide valuable information regarding the feasibility of intensifying the inclusion of FBDG in the primary-school curriculum. This is possible because the primary-school curriculum is a national curriculum and the South African FBDG were initially tested and found applicable and acceptable on a national level ${ }^{(12)}$. A substantial limitation to the study was that the methodology involved a selfcompleted questionnaire. Many participants refrained from completing some of the questions, leading to a lack of depth in the collected data.

\section{Recommendations}

The following recommendations are made based on the study's outcomes, taking into account the newly launched Integrated School Health Policy framework.

The Department of Education needs to consider implementing FBDG more extensively and not only in the Life Skills curriculum and in limited grades. Additionally, appropriate training for educators should aim at equipping them to make use of the FBDG either through the formal curriculum or through nutrition education programmes. Another benefit of training educators in the FBDG is to 
help them improve their own lifestyles and thereby act as role models to their learners. Moreover, training also needs to address concerns about having the necessary finances to eat healthily by conveying the perception 'You don't have to be wealthy to have a balanced diet' into the classroom. The Department of Education can use the National School Nutrition Programme as a vehicle for FBDG interventions through the meals provided to learners.

School principals, management staff and school governing bodies should provide the necessary support and encourage a healthy school environment where the FBDG could be implemented as part of school policies. The school food policy should be developed and implemented according to health-promoting school principles to support healthy eating at schools. This includes the provision of healthy food at tuck shops and school events as well as bringing healthy lunch boxes to school. Principals could also take the lead in educating parents about FBDG through the school parent meetings.

Various strategies for FBDG interventions can thus be developed and implemented at schools. These guidelines offer the possibility to succeed in implementing the FBDG, not only in terms of the curriculum, but also through the Integrated School Health Policy in South Africa.

The present study should be repeated in other provinces in the country to assess opinions of more educators about the feasibility of implementing FBDG in the national curriculum for primary schools. Future research is needed to explore educators' knowledge and practices on healthy nutrition and lifestyle whereby they can act as role models to their learners through influencing them to accept these messages.

\section{Conclusions}

Findings from our study indicated that implementing FBDG in the national school curriculum is feasible and of importance alongside optimizing the school physical environment through the health-promoting school concept. Key factors required for successful implementation in the curriculum are sufficient educational materials, adequate time allocation and appropriate educator training. The new Integrated School Health Policy sheds light on the opportunity to implement FBDG in school settings through the national school curriculum and co-curricular or school-based activities. Furthermore, our findings have highlighted the importance of implementing these guidelines more intensively in the national primaryschool curriculum as a nutrition education tool.

\section{Acknowledgements}

Sources of funding: Partial funding for this study was received from the South African Sugar Association (grant no. 225). This funder had no role in the design, analysis or writing of this article. Conflicts of interest: The authors declare they do not have anything to disclose regarding funding or conflict of interest which adversely could have influenced the investigation. Authors' contributions: The primary author acknowledges her supervisors as co-authors. K.A.N.: principal investigator and drafting of the manuscript. Ad.V.: overall supervision of the study and acquisition and interpretation of the data. J.M.F.: critical revision and editing of the paper and submission of the final draft. L.T.B.: study concept and design and revision of the manuscript. M.K.H.: study concept and design, critical revision of the manuscript and responsible for the accuracy of the data analyses. Acknowledgements: The authors are grateful to the Western Cape Department of Education for granting permission to conduct the study, and particularly the South African Sugar Association for funding. Great appreciation goes to all the educators, school principals and curriculum advisors who voluntarily participated in the study.

\section{References}

1. Food and Agriculture Organization of the United Nations (2001) Report of the Regional Expert Consultation of the Asia-Pacific Network for Food and Nutrition on Reviewing Implementation of National Food Based Dietary Guidelines (FBDGS). Bangkok: FAO, Regional Office for Asia and the Pacific.

2. European Food Information Council (2009) Summary Report of a Workshop on Food Based Dietary Guidelines, Budapest, Hungary. Brussels: EUFIC.

3. World Health Organization (2009) Summary Report: Interventions on Diet and Physical Activity: What Works? Geneva: WHO.

4. World Health Organization (2011) Global status report on non-communicable diseases, 2010: Description of the global burden of NCDs, their risk factors and determinants. http://www.who.int/nmh/publications/ncd_report2010/en/ (accessed June 2011).

5. World Health Organization (2012) World Health Statistics 2012: Part II: Highlighted topics. http://www.who.int/gho/ publications/world_health_statistics/EN_WHS2012_Part2.pdf (accessed January 2013).

6. Department of Health (2007) South Africa Demographic and Health Survey 2003. Pretoria: DOH.

7. Armstrong MEG, Lambert MI, Sharwood KA et al. (2006) Obesity and overweight in South African primary school children - the Health of the Nation Study. S Afr Med J 96, 439-444.

8. Labadarios D (editor) (2007) The National Food Consumption Survey - Fortification Baseline (NFCS-FB): South Africa, 2005. Stellenbosch: DOH.

9. Reddy SP, James S, Sewpaul R et al. (2010) Umthente Uhlaba Usamila - The South African Youth Risk Behaviour Survey 2008. Cape Town: South African Medical Research Council.

10. Durão S (2011) The anthropometric nutritional status of children 0-18 years old in the Western Cape Province of South Africa: a systematic review. Masters Dissertation, University of Cape Town.

11. Department of Health (2004) South African Guidelines for Healthy Eating. Pretoria: DOH. 
12. Vorster H, Love P \& Browne C (2001) Development of food based dietary guidelines for South Africa - the process. S Afr J Clin Nutr 14, Suppl., S3-S6.

13. Food and Agriculture Organization of the United Nations \& World Health Organization (1998) Preparation and Use of Food Based Dietary Guidelines. Technical Report. Rome: FAO.

14. Giroux HA (1988) Teachers as Intellectuals: Toward a Critical Pedagogy of Learning. Westport, CT: Bergin \& Garvey.

15. Keller I \& Lang T (2008) Food-based dietary guidelines and implementation: lessons from four countries - Chile, Germany, New Zealand and South Africa. Public Health Nutr 11, 867-874.

16. Albert J (2007) Global patterns and country experiences with the formulation and implementation of food-based dietary guidelines. Ann Nutr Metab 5, 2-7.

17. Department of Education (2005) South African National Curriculum Statement for Life Orientation: Grade R-9. Pretoria: DOE.

18. Van Deventer KJ (2009) Perspectives of teachers on the implementation of Life Orientation in grades R-11 from selected Western Cape schools. S Afr J Educ 29, 127-145.

19. Department of Education (2010) Curriculum and Assessment Policy Statement (CAPS). http://www.thutong.doe.gov.za (accessed September 2010).

20. Department of Health (2004) Strategic Priorities for the National Health System, 2004-2009. Pretoria: DOH.

21. Department of Health (2012) Integrated School Health Policy. http://www.doh.gov.za/docs/policy/2012/ Integrated_School_Health_Policy.pdf (accessed May 2013).

22. CREATE Consortium for Research on Education Access, Transitions and Equity (2009) "No Fee" Schools in South Africa. Policy Brief Number 1. http://www.create-rpc.org/ policy/southafricapb/ (accessed March 2011).

23. Western Cape Department of Education (2007) Funding Allocations and School Subsidies. Media Release. http:// www.wced.wcape.gov.za/comms/press/2007/71_subsidy.html (accessed March 2011).

24. Rooth E (2005) An investigation of the status and practice of Life Orientation in South African schools in two provinces. PhD Thesis, University of the Western Cape.
25. Labadarios D, Steyn NP, Maunder E et al. (2005) The National Food Consumption Survey (NFCS): South Africa, 1999. Public Health Nutr 8, 533-543.

26. Wolmarans P, Jooste P, Oelofse A et al. (1995) Breakfast patterns of South African primary school children in low socio-economic areas. S Afr J Food Sci Nutr 7, 103-106.

27. Steyn NP, Badenhorst CJ \& Nel JH (1993) The meal pattern and snacking habits of schoolchildren in two rural areas of Lebowa. S Afr J Food Sci Nutr 5, 5-9.

28. Bourne LT, Langenhoven ML, Steyn K et al. (1993) Nutrient intake in the urban African population of Cape Peninsula, South Africa. The Brisk study. Cent Afr J Med 39, 238-247.

29. Wardle J, Parmenter K \& Waller J (2000) Nutrition knowledge and food intake. Appetite 34, 269-275.

30. Oldewage-Theron WH \& Egal AA (2010) Nutrition knowledge and nutritional status of primary school children in QwaQwa. S Afr J Clin Nutr 23, 149-154.

31. Glasauer P, Aldinger C, Sen-Hai YU et al. (2003) Nutrition as an entry point for health-promoting schools: lessons from China. ftp://ftp.fao.org/es/esn/nutrition/china_fna33.pdf (accessed December 2011).

32. De Villiers A, Draper CE, Fourie JM et al. (2012) 'Health Kick': formative assessment of the health environment in low-resource primary schools in the Western Cape Province of South Africa. BMC Public Health 12, 794.

33. Temple NJ, Steyn NP, Myburgh NG et al. (2006) Food items by students attending schools in different socio-economic areas in Cape Town, South Africa. Nutrition 22, 252-258.

34. Marraccini T, Meltzer S, Bourne LT et al. (2012) A qualitative evaluation of exposure to and perceptions of the Woolworths Healthy Tuck Shop Guide in Cape Town, South Africa. http://online.liebertpub.com/doi/pdf/ 10.1089/chi.2012.0034 (accessed January 2013).

35. Bekker F (2012) The provision of healthy food in a school tuck shop: does it influence Bloemfontein primary school learners' perceptions, attitudes and behaviour towards healthy eating? Masters Thesis, University of Stellenbosch.

36. Linda C (2005) Educator Workload in South Africa. Cape Town: Human Science Research Council Press.

37. Draper CE, Nemutandani SM, Grimsrud AT et al. (2010) Evaluation of a school-based physical activity intervention in Alexandra Township. S Afr J Sport Med 22, 12-19. 